\title{
АСМ-АНАЛИЗ ПОВЕРХНОСТИ ПРОФИЛИРОВАННОЙ СУЛЬФОКАТИОНООБМЕННОЙ МЕМБРАНЫ ПОСЛЕ КОНТАКТА С ФЕНИЛАЛАНИНОМ
}

\author{
() 2018 Е. А. Голева, В. И. Васильева, Е. О. Абрамова \\ Воронежский государственный университет, Университетская пл., 1, 394018 Воронеж, Россия \\ e-mail:vorobjeva_ea@mail.ru
}

Поступила в редакцию 01.08.2018

\begin{abstract}
Аннотация. Методом атомно-силовой микроскопии исследована неоднородность поверхности профилированной сульфокатионообменной мембраны после химического кондиционирования и контакта с водными растворами фенилаланина. Определены микропрофили, гистограммы плотности распределения значений высот и стандартные амплитудные параметры шероховатости поверхности образцов мембраны МК- $40_{\text {пр }}$. Установленные различия в структуре и возрастание однородности поверхности мембраны после контакта с аминокислотой связано с уменьшением количества и размеров макропор и крупных дефектов поверхности вследствие сорбции аминокислоты.
\end{abstract}

Ключевые слова: профилированная сульфокатионообменная мембрана, атомно-силовая микроскопия, фенилаланин.

DOI: https://doi.org/10.17308/kcmf.2018.20/578

\section{ВВЕДЕНИЕ}

Ионообменные мембраны обладают неоднородной и шероховатой поверхностью, что влияет на их эксплуатационные, физико-химические, транспортные и равновесные характеристики [1-5]. Существуют несколько способов изучения структуры поверхности полимерных мембран: атомно-силовая микроскопия (АСМ), сканирующая электронная микроскопия (СЭМ), методы светорассеяния излучения в различных длинах волн и т. д. [6-11]. Атомно-силовая микроскопия позволяет выявлять особенности геометрии поверхности материалов с нанометровым разрешением без предварительной обработки и специальной пробоподготовки, что особенно важно при исследовании ионообменных мембран. Таким образом, мембраны не претерпевают структурных преобразований и изучаются в неизмененном состоянии. Метод обладает высоким разрешением, точностью и воспроизводимостью. Последующая цифровая обработка АСМ-данных дает возможность глубокого анализа различных характеристик поверхности. Количественная оценка шероховатости поверхности ионообменных мембран имеет важное практическое значение, так как позволяет выявить влияние различных факто- ров на процессы переноса ионов и молекул в мембранных процессах [12-16].

В работах $[17,18]$ показано, что после контакта с аминокислотами увеличивается шероховатость поверхности гомогенных мембран и, напротив, поверхность гетерогенных мембран становится более гладкой. АСМ-анализ поверхности анионообменных гетерогенной MA-41 и гомогенной AMT мембран в аминокислотной форме выявил выпадение кристаллов тирозина при его поглощении ионообменным материалом из достаточно концентрированных растворов, что приводит к изменению транспортных и электрохимических характеристик этих мембран [19].

Цель данной работы - установление влияния алкилароматической аминокислоты фенилаланина на свойства поверхности (микрорельеф и шероховатость) гетерогенной профилированной сульфокатионообменной мембраны МК-40.

\section{ЭКСПЕРИМЕНТАЛЬНАЯ ЧАСТЬ}

Объекты исследования. Объектом исследования являлась гетерогенная сульфокатионообменная мембрана МК-40 с геометрически неоднородной (профилированной) поверхностью. Гетерогенные ионообменные мембраны представляют собой 
композиты ионообменных смол, полиэтилена низкого давления и армирующей ткани (капрон). Катионообменная мембрана МК-40, изготовленная на основе сильнокислотного сульфокатионообменника КУ-2×8, представляет собой композицию из полиэтилена и сульфированного сополимера стирола и дивинилбензола. Способ профилирования гетерогенных мембран в набухшем состоянии разработан в ООО «Инновационное предприятие «Мембранная технология» (г. Краснодар) и защищен патентом (рис. 1) [20].

Образцы профилированных мембран изготавливались методом горячего прессования с получением заданного геометрического рельефа поверхности при температуре от 20 до $140{ }^{\circ} \mathrm{C}$, давлении 10-13 МПа и времени выдержки под давлением от 10 с до 10 мин. Поверхность профилированной мембраны в сухом состоянии обычно представляет собой совокупность полусфер радиусом 0.5 мм, расположенных друг от друга на расстоянии 1.5 мм в шахматном порядке [21]. Во впадинах между полусферами на поверхности мембраны находятся выходы армирующей сетки. После набухания в воде в мембране образуются отдельные фазы: активная ион-проводящая фаза, в которой локализованы ионогенные группы (фаза геля или ионита) и непроводящая фаза инертного связующего полиэтилена. Поровое пространство между этими фазами заполнено равновесным раствором, который образует третью фазу.

Сравнительный АCM-анализ проводился на воздушно-сухих образцах мембран после химического кондиционирования и после контакта с фенилаланином в течение 80 часов. Химическое

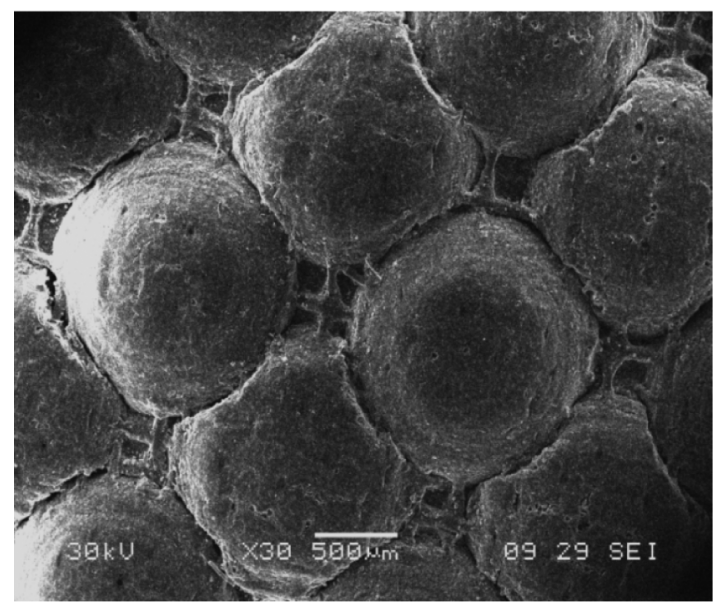

$a$ кондиционирование мембран проводили по общепринятой методике [22] последовательной обработкой растворами кислот и щелочей и переводом в требуемую ионную форму - водородную. Модельный водный раствор фенилаланина концентрации 0.15 моль/дм³ готовили из реактива классификации «ч.д.а.».

Исследование мембран. Изучение микрорельефа поверхности мембраны проводили методом АСМ с помощью сканирующего зондового микроскопа корпорации NT-MDT модели Solver P47 Pro (Россия, г. Зеленоград) в полуконтактном режиме на воздушно-сухих образцах. Сканирование осуществляли кантилеверами типа NSG20 длиной $90 \pm 5$ мкм, резонансной частотой 260-630 кГц и радиусом кривизны острия зонда не более 10 нм. Кантилевер был подобран с учетом мягкости структуры поверхности мембран. Эксперименты проводили на воздухе при температуре $25 \pm 1^{\circ} \mathrm{C}$. Чувствительность зонда и точность сканера атомно-силового микроскопа позволили получить изображения поверхности с латеральным разрешением до 10 нм и вертикальным до 1 нм.

Изучение поверхности ионообменной мембраны проводили в двух режимах: топографии и фазового контраста. В режиме топографии фиксировали рельеф поверхности. Режим фазового контраста позволяет распознать области, отличающиеся по химическому составу, адгезионным и упругим свойствам [23, 24]. Если отдельные участки поверхности имеют различные свойства, то изображение будет иметь дополнительный контраст, зависящий от природы материала на отдельных участках. Он проявляется в изменении фазы колебаний зонда,

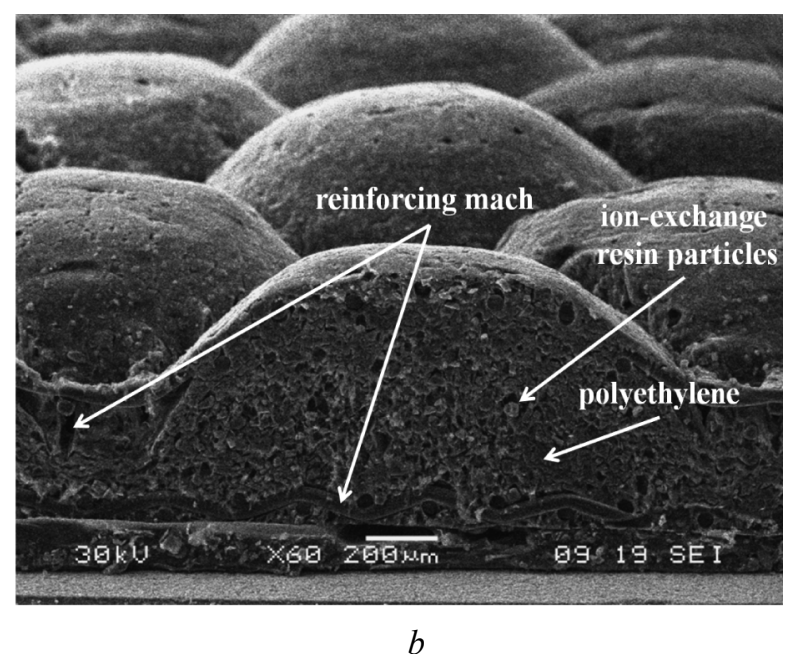

Рис. 1. Микрофотографии кондиционированного образца профилированной сульфокатионообменной мембраны МК-40 вр сухом состоянии

[Fig. 1. Micrographs of the conditioned sample of the profiled MK- $40_{\mathrm{pr}}$ sulfocation-exchange membrane in the dry state] 
в то время как амплитуда колебаний отражает топографию поверхности. Детектирование фазы колебаний одновременно с получением топографии поверхности при амплитудном детектировании положения зонда в обратной связи позволяет из сравнения амплитудного и фазового изображений получить информацию о фазовом составе образца (так называемый фазовый контраст).

Визуализация рельефа представлялась в виде двумерных и трёхмерных цифровых изображений поверхности [25]. На топографических картах (высота отображается цветом) проводили сечения, вдоль которых строился профиль поверхности. Анализ полученных АСМ-изображений осуществлялся с помощью программного обеспечения ACM Solver P47 Pro Nova RC1 и заключался в определении амплитудных среднестатистических параметров шероховатости поверхности в соответствие с международными стандартами ISO 4287/1 и ANSI В. 46.1: $R_{y}$ - размах высот (максимальный перепад высот между самой верхней и нижней точками поверхности профиля), $R_{a}-$ средняя арифметическая шероховатость, $R_{q}$ - средняя квадратичная шероховатость, $R_{z}$ - шероховатость поверхности по выбранным десяти максимальным высотам и впадинам [26].

Пробоподготовка заключалась в закреплении фрагмента мембраны на предметном столике с помощью двухстороннего углеродного скотча и обработке поверхности этиловым спиртом для удаления инородных частиц окружающей среды. АCMизображения снимали на выступах профиля поверхности мембраны.

\section{РЕЗУЛЬТАТЫ И ИХ ОБСУЖДЕНИЕ}

На рис. 2 представлены результаты АСМ-сканирования в режиме топографии поверхности образцов мембран МК- $40_{\text {пр }}$ до и после контакта с фенилаланином концентрации 0.15 моль/дм ${ }^{3}$ в течение 80 часов. На трехмерных изображениях поверхности мембран видно, что их поверхность не является плоской, на ней имеются неровности, распределенные хаотично. Многочисленные темные участки, т.е. самые низкие по высоте, интерпретируются как поры. Сравнительный анализ АСМ-изображений поверхности мембраны МК-40 пр при различных размерах площади сканирования выявил изменения рельефа поверхности при изменении масштабов сканирования. При площади сканирования $10 \times 10$ мкм заметны более крупные фрагменты рельефа по сравнению с площадью сканирования $2 \times 2$ мкм.
Для мембраны после контакта с фенилаланином установлен более сглаженный рельеф поверхности по сравнению с кондиционированным образцом из-за сорбции аминокислоты вследствие электростатических взаимодействий биполярных ионов ароматической нейтральной аминокислоты с заряженными фиксированными группами сульфокатионообменника как на поверхности, так и на стенках в порах мембраны. Авторами работ [17] при оценке влияния сорбции основной аминокислоты лизина на состояние поверхности гетерогенной сульфокатионообменной мембраны МК-40 с гладкой поверхностью также установлено повышение однородности ее поверхности. По мнению авторов при сорбции аминокислот гетерогенной катионообменной мембраной происходит уменьшение количества и размеров как нанопор, так и крупных дефектов.

Анализ микропрофилей на выступах поверхности мембраны МК- $40_{\text {пр }}$ (рис. 3) подтверждает факт уменьшения шероховатости поверхности в аминокислотной форме, что связано с уменьшением размеров крупных пор, представляющих собой промежутки между частицами ионообменника и полиэтиленовой основой мембраны. В работах [27-29] при оценке гидратации мембраны МК-40 в формах основных аминокислот установлено, что взаимодействие аминокислот с мембраной вызывает снижение влагосодержания мембраны. Полученные нами методом гравиметрии результаты по влагосодержанию исследуемых образцов профилированной мембраны подтверждают факт уменьшения содержания воды в мембране после контакта с фенилаланином $[9,30]$. К тому же, процесс не ограничивается ионным обменом, важную роль играют гидрофобные эффекты [30]. Адсорбционные слои, состоящие из ионов аминокислот, гидрофобизируют поверхность частиц ионообменника, повышая адгезию к неполярной полимерной матрице (полиэтилен). Подобный эффект наблюдался также при сорбции алкиламинов и четвертичных аммониевых оснований гетерогенными мембранами на основе ионообменников КУ-2*8 [31]. Сорбция аминокислот способствует интенсивному структурообразованию в системе ионообменник - полимерный носитель [30, 32-34], что вызывает уменьшение размера крупных пор в местах контакта двух фаз.

Дополнительную информацию о состоянии исследуемой поверхности образцов мембран после химического кондиционирования и после контакта с фенилаланином дает анализ изображений, полученных в режиме фазового контраста (рис. 4). При- 

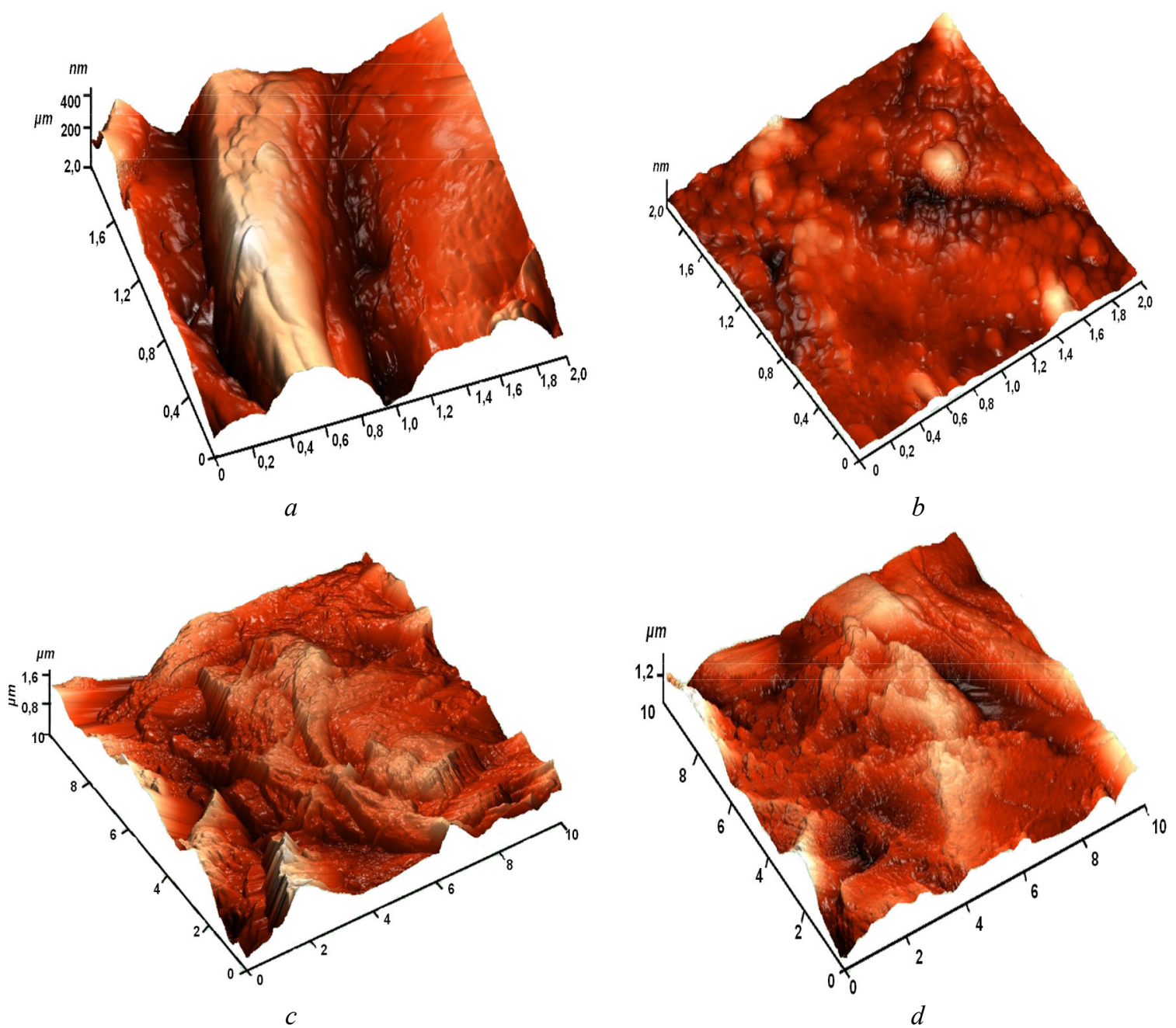

Рис. 2. Трехмерные АСМ-изображения на выступах поверхности профилированной сульфокатионообменной мембраны МК-40 пр до $(a, c)$ и после $(b, d)$ контакта с фенилаланином концентрации $C_{0}=0.15$ моль/дм ${ }^{3}$ в течении 80 часов Площадь сканирования $2 \times 2$ мкм $(a, b)$ и $10 \times 10$ мкм $(c, d)$

[Fig. 2. Three-dimensional AFM images on the protrusions of the surface of the profiled MK- $40_{\mathrm{pr}}$ sulfocation-exchange membrane before $(a, c)$ and after $(b, d)$ its contact with phenylalanine concentration $C_{0}=0.15 \mathrm{~mol} / \mathrm{L}$ for 80 hours. The scanning area is $2 \times 2 \mu \mathrm{m}(a, b)$ and $10 \times 10 \mu \mathrm{m}(c, d)]$

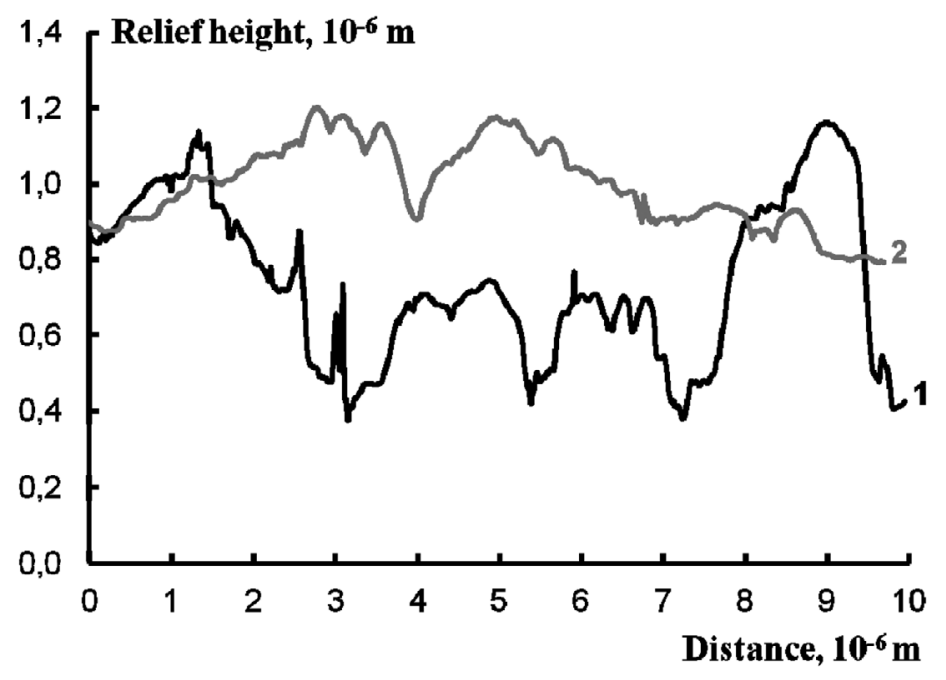

Рис. 3. Микропрофили на выступах поверхности сульфокатионообменной мембраны МК-40 пр до (кривая 1) и после (кривая 2) контакта с фенилаланином концентрации $C_{0}=0.15$ моль $/$ дм $^{3}$ в течении 80 часов. Площадь сканирования

$$
10 \times 10 \text { мкм }
$$

[Fig. 3. Microprofiles on the protrusions of the surface of MK-40 pr sulfocation-exchange membrane before (curve 1) and after (curve 2) its contact with phenylalanine concentration $C_{0}=0.15 \mathrm{~mol} / \mathrm{L}$ for 80 hours. The scanning area is $10 \times 10 \mu \mathrm{m}]$ 


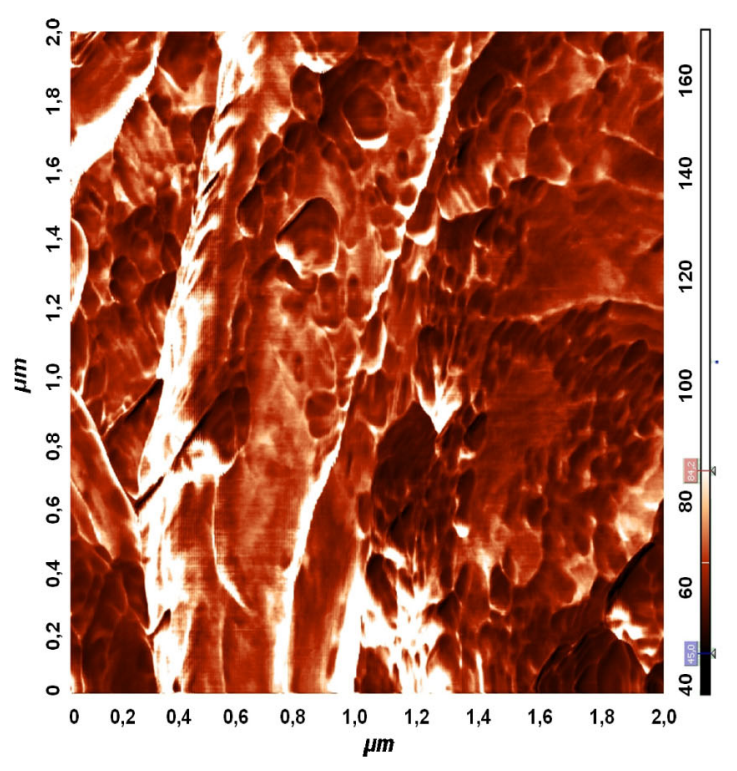

$a$

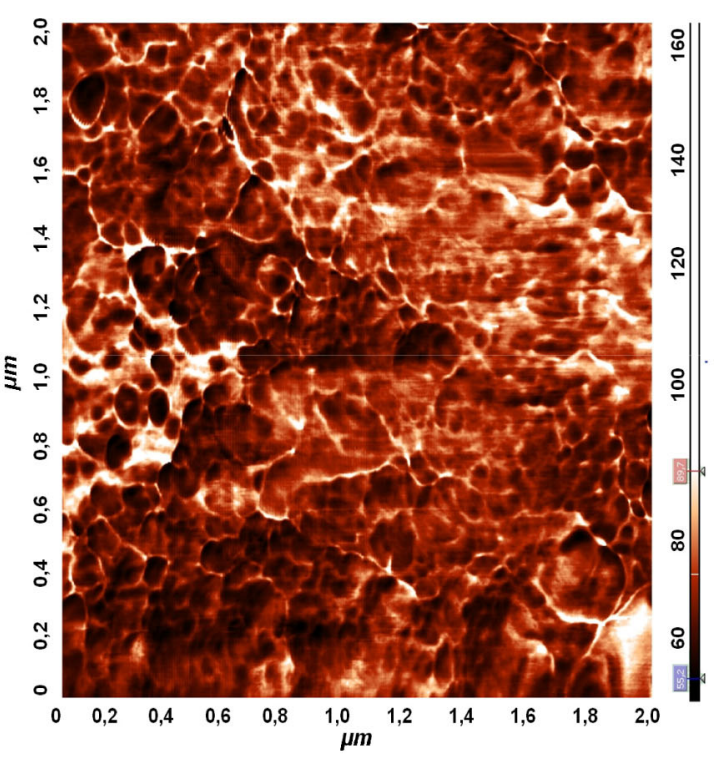

$b$

Рис. 4. Фазовые изображения на выступах поверхности профилированной сульфокатионообменной мембраны MК-40 пр до $(a)$ и после $(b)$ контакта с фенилаланином концентрации $C_{0}=0.15$ моль/дм ${ }^{3}$ в течении 80 часов. Площадь сканирования $2 \times 2$ мкм

[Fig. 4. Phase images on the protrusions of the surface of the profiled MK-40 $0_{\mathrm{pr}}$ sulfocation-exchange membrane before (a) and after $(b)$ its contact with phenylalanine concentration $C_{0}=0.15 \mathrm{~mol} / \mathrm{L}$ for 80 hours. The scanning area is $\left.2 \times 2 \mu \mathrm{m}\right]$

менение метода фазового контраста позволило визуализировать различные поверхностные изменения, которые не имеют топографического проявления и выявляются только на изображении детектирования фазы колебаний. Получение изображения смещения фазы колебаний кантилевера (рис. 4) параллельно с топографическим изображением поверхности (рис. $2 a$ ) позволяют получить дополнительную информацию об изменении различных свойств поверхности образца (в частности, связанных с изменением диссипации энергии колебаний кантилевера от одной точки поверхности к другой). Метод отображения фазы (фазовый контраст) позволил зарегистрировать неоднородность свойств исследуемой поверхности мембраны (химическая гетерогенность). При этом на изображениях поверхности гетерогенной мембраны границы раздела фаз совпадают с крупными поверхностными дефектами (разрывы, микротрещины), что видно при сравнении рис. $2 a, 2 b$ и рис. $4 a, 4 b$ соответственно.

На фазовых изображениях более светлые области соответствуют большим значениям диссипации энергии и большим значениям сдвига фазы колебания зонда в результате взаимодействия с исследуемой поверхностью, что характеризует ее свойства, в том числе гидрофобность $[17,35]$. В работах $[17,28]$ показано, что важным фактором, определяющим контраст фазовых изображений, являют- ся различия в адгезии зонда из-за неоднородного распределения поверхностной воды на поверхности перфторированных сульфокатионообменных мембран. При переходе от водородной к аминокислотной форме значение сдвига фазы увеличивалось в три-четыре раза, что указывает на изменение свойств поверхности. Это является подтверждением гидрофобизации поверхности, уменьшения влагосодержания, а также изменения распределения заряда на поверхности мембраны в форме аминокислоты.

Количественно геометрическая неоднородность поверхностей исследуемых мембран была охарактеризована с помощью величин максимального перепада высот $R_{y}$ среднеарифметической шероховатости $R_{a}$, среднеквадратичной шероховатости $R_{q}$ и шероховатости поверхности $R_{z}$ по десяти максимальным высотам и впадинам, приведенных в табл. 1. Поверхность кондиционированного образ-

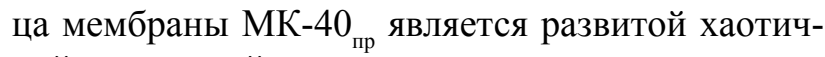
ной структурой с шероховатостью в микрометрическом масштабе: средний масштаб шероховатости выше, чем для мембраны после контакта с фенилаланином, и $R_{\text {a }}$ соответствует 186.4 нм при шероховатости поверхности $R_{\mathrm{z}}=953.1$. Влияние фенилаланина приводит к снижению величин всех амплитудных параметров поверхности по сравнению с кондиционированной мембраной 
Таблица 1. Параметры шероховатости поверхности профилированной сульфокатионообменной мембраны МК-40 пр в воздушно-сухом состоянии. Площадь сканирования $10 \times 10$ мкм

[Table 1. Surface roughness parameters of the profiled MK- $40_{\mathrm{pr}}$ sulfocation-exchange membrane in the air-dry state. The scanning area is $10 \times 10 \mu \mathrm{m}]$

\begin{tabular}{|c|c|c|c|c|}
\hline $\begin{array}{c}\text { Образец мембраны } \\
\text { [Mеmbrane sample] }\end{array}$ & $\begin{array}{c}R_{\mathrm{y}}, \mathrm{HM} \\
{\left[R_{\mathrm{y}}, \mathrm{nm}\right]}\end{array}$ & $\begin{array}{c}R_{\mathrm{z}}, \mathrm{HM} \\
{\left[R_{\mathrm{z}}, \mathrm{nm}\right]}\end{array}$ & $\begin{array}{c}R_{\mathrm{a}}, \mathrm{HM} \\
{\left[R_{\mathrm{a}}, \mathrm{nm}\right]}\end{array}$ & $\begin{array}{c}R_{\mathrm{q}}, \mathrm{HM} \\
{\left[R_{\mathrm{q}}, \mathrm{nm}\right]}\end{array}$ \\
\hline $\begin{array}{c}\text { Кондиционированный } \\
\text { [Сonditioned] }\end{array}$ & 1901.7 & 953.1 & 186.4 & 239.5 \\
\hline $\begin{array}{c}\text { После контакта с фенилаланином } \\
\text { [After contact with phenylalanine] }\end{array}$ & 1487.8 & 745.0 & 172.8 & 217.9 \\
\hline
\end{tabular}

МК-40 пр. После контакта с фенилаланином поверхность мембраны МК-40 пр становится относительно однородной: шероховатость поверхности $R_{\mathrm{z}}$ соответствует 745.0 нм, а средний масштаб шероховатости $R_{\mathrm{a}}-172.8 \mathrm{нм.}$

Гистограммы плотности распределения значений высот на поверхности профилированной сульфокатионообменной мембраны МК-40 пр приведены на рис. 5. Сопостовление гистограмм плотности распределения по высотам поверхности выявило, что для кондиционированного образца характерно более узкое распределение высот. Самая высокая плотность (500) соответствует среднему значению шероховатости $1 \cdot 10^{-6}$ м. Для образца мембраны МК-40 пр после контакта с фенилаланином гистограмма характеризуется размытым

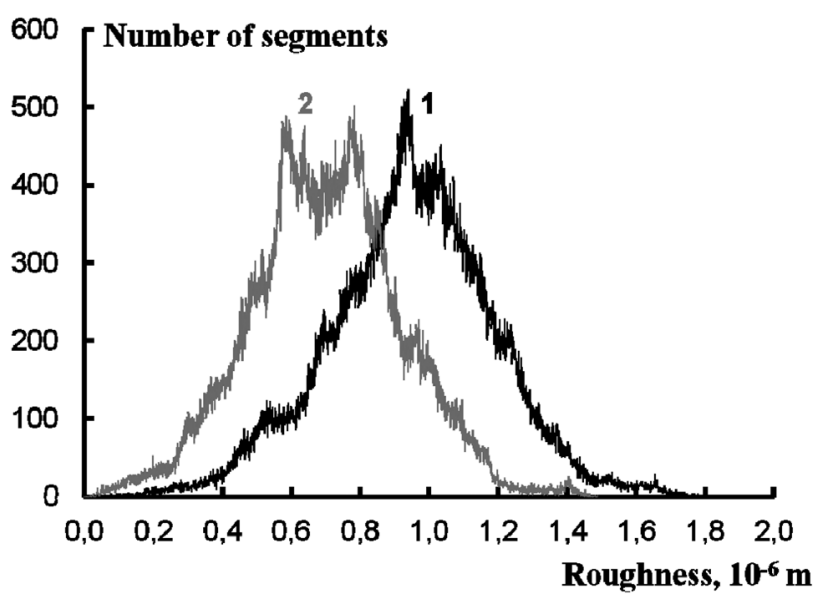

Рис. 5. Гистограммы плотности распределения значений высот на выступах поверхности мембраны $\mathrm{MK}-40_{\text {пр }}$ до (1) и после (2) контакта с фенилаланином концентрации $C_{0}=0.15$ моль $/$ дм $^{3}$ в течении 80 часов. Площадь сканирования $10 \times 10$ мкм

[Fig. 5. Histograms of the density of the height value distribution on the protrusions of the surface of $\mathrm{MK}-40_{\mathrm{pr}}$ membrane before (1) and after (2) its contact with phenylalanine concentration $C_{0}=0.15 \mathrm{~mol} / \mathrm{L}$ for 80 hours. The scanning area is $10 \times 10 \mu \mathrm{m}$ ] максимумом с уменьшением среднего значения шероховатости до $6 \cdot 10^{-7}-8 \cdot 10^{-7}$ м при значении максимальной плотности распределения (500).

\section{ЗАКЛЮЧЕНИЕ}

Методом атомно-силовой микроскопии выявлен характер воздействия ароматической аминокислоты фенилаланина на свойства поверхности профилированной сульфокатионообменной мембраны МК-40 . Установлено сглаживание микрорельефа поверхности мембраны после контакта с аминокислотой, связанное с уменьшением количества и размеров макропор и крупных дефектов поверхности мембраны вследствие сорбции фенилаланина. Анализ полученных микропрофилей поверхности мембраны позволил установить, что отдельные неоднородности рельефа кондиционированной мембраны МК-40 пр в воздушно-сухом состоянии имели модуляции по высоте 0.19 мкм, а шероховатость поверхности характеризовалась размером 0.95 мкм. У образца мембраны после контакта с фенилаланином отмечено уменьшение размаха высот и степени шероховатости поверхности, средние величины которых составили $14.9 \cdot 10^{-7}$ и $7.5 \cdot 10^{-7}$ м соответственно. Полученные гистограммы плотности распределения высот на поверхности мембраны демонстрируют после контакта с аминокислотой смещение распределения в сторону меньших величин.

Работа выполнена при финансовой поддержке РФФИ (проект № 18-08-01260).

АСМ-изображения поверхности мембраны были получены на оборудовании Центра коллективного пользования Воронежского государственного университета. URL: http://ckp.vsu.ru.

\section{СПИСОК ЛИТЕРАТУРЫ}

1. Березина Н. П., Кононенко Н. А. Структурная организация ионообменных мембран. Краснодар, Изд-во Кубан. гос. ун-та, 1996, 49 с. 
2. Певницкая М. В., Варенцов В. К., Урусов К. Х. // Изв. СО АН СССР. Сер хим. наук, 1969, вып. 6, № 4, c. $18-24$.

3. Варенцов В. К., Певницкая М. В. // Изв. СО АН СССР. Сер хим. наук, 1973, вып. 2, № 4, с. 3-8.

4. Письменская Н. Д., Никоненко В. В., Белова Е. И., Лопаткова Г. Ю., Систа Ф., Пурсели Ж., Ларше К. // Электрохимия, 2007, т. 43, № 3, с. 325-345.

5. Сазанова Т. С., Воротынцев И. В., Куликов Б. В., Давлетбаева И. М., Зарипов И. И. // Мембраны и мембранные технологии, 2016, т. 6, № 2, с. 166-175.

6. Голева Е. А., Васильева В. И. // Вестник ВГУ. Серия: Химия, Биология, Фармация, 2012, № 1, с. 3338.

7. Tamime R., Wyart Y., Siozade L., Baudin I., Deumie C., Glucina K., Moulin P. // Membranes, 2011, vol. 1, pp. 91-97.

8. Volfkovich Yu. M., Filippov A. N., Bagotsky V. S. Structural Properties of Porous Materials and Powders Used in Different Fields of Science and Technology. London, Springer-Verlag, 2014, p. 300.

9. Васильева В. И., Голева Е. А. // Поверхность. Рентгеновские, синхротронные и нейтронные исследования, 2013, № 6, с. 45-50.

10. Васильева В. И., Кранина Н. А., Малыхин М. Д., Акберова Э. М., Жильцова А. В. // Поверхность. Рентгеновские, синхротронные и нейтронные исследования, 2013, № 2, с. 51-561.

11. Яцев А. М., Акберова Э. М., Голева Е. А., Васильева В. И., Малыхин М. Д. // Сорбционнье и хроматографические процессы, 2017, т. 17, № 2, с. 313-322.

12. Письменская Н. Д. Дисс. ... д-ра хим. наук. Краснодар, 2004, 405 с.

13. Лопаткова Г. Ю. Дисс. ... канд. хим. наук. Краснодар, 2006, 180 c.

14. Зайченко Н. А., Васильева В. И., Григорчук О. В., Гречкина М. В., Богатиков Е. В. // Вестник ВГУ. Серия: Химия, Биология, Фармачия, 2009, № 1, с. 7-16.

15. Васильева В. И., Письменская Н. Д., Акберова Э. М., Небавская К. А. // Журн. физ. химии, 2014, т. 88, № 7-8, c. 1114-1120.

16. Васильева В. И., Битюцкая Л. А., Зайченко Н. А., Гречкина М. В., Ботова Т. С., Агапов Б. Л. // Сорбциионные и хроматографические прочессы, 2008, т. 8, № 2, c. 260-271.

17. Крисилова Е. В., Елисеева Т. В., Орос Г. Ю. // Физикохимия поверхности и защита материалов, 2011, т. 47 , № 1, c. $36-39$.
18. Suwal S., Roblet C., Amiot J., Bazinet L. // Sep. Purif. Technol., 2015, vol. 147, p. 227-236.

19. Харина А. Ю. Дисс. ... канд. хим. наук. Воронеж, $2017,162 \mathrm{c}$.

20. Заболоцкий В. И., Лоза С. А., Шарафан М. В. Патент РФ, № 2284851, 2006.

21. Заболоцкий В. И., Лоза С. А., Шарафан М. В. // Электрохимия, 2005, т. 41, № 10, с. 1185-1192.

22. Березина Н. П., Кононенко Н. А., Дворкина Г. А., Шельшедов Н. В. Физико-химические свойства ионообменных материалов. Краснодар, Кубанский государственный университет, 1999, 82 с.

23. Рыков С. А. Сканирующая зондовая микроскопия полупроводниковых материалов и наноструктур. СанктПетербург, Наука, 2001, 53 с.

24. Khulbe K. C., Feng C. Y., Matsuura T. Synthetic Polymeric Membranes. Characterization by Atomic Force Microscopy. Berlin Heidelberg, Springer_Verlag, 2008, $197 \mathrm{p}$.

25. Сканирующая зондовая микроскопия биополимеров / под ред. И. В. Яминского. М.: Научный мир, $1997,88 \mathrm{c}$.

26. Шероховатость поверхности. Параметры и характеристики. ГОСТ 2789-73. Введ. 1973-04-23. М.: Изд-во стандартов, 1973, 6 с.

27. Крисилова Е. В., Елисеева Т. В., Селеменев В. Ф. // Журн. физ. химии, 2009, т. 83, № 11, с. 2145-2147.

28. Крисилова Е. В., Елисеева Т. В., Селеменев В. Ф. // Сорбционные и хроматографические прочессы, 2009, т. 9, вып. 5, с. 671-676.

29. Котова Д. Л., Селеменев В. Ф. Термический анализ ионообменных материалов. М.: Наука, 2002, 156 с.

30. Голева Е. А., Васильева В. И., Селеменев В.Ф., Кузнецов В.А., Останкова И. В. // Сорбичионные и хроматографические прочессы, 2016, т. 16, № 5, с. 640652.

31. Ласкорин Б. Н, Семенова Е. И., Смирнова Н. М. Сб.: Синтез и свойства ионообменных материалов. М.: Наука, 1968, 10 с.

32. Трунаева Е. С., Хохлова О. Н., Хохлов В. Ю. // Журн. структур. химии, 2015, т. 56, № 6, с. 1111-1115.

33. Васильева В. И., Голева Е. А., Селеменев В. Ф. // Журн. физ. химии, 2016, т. 90, № 10, с. 1548-1557.

34. Котова Д. Л., Крысанова Т. А., Рыжнова О. И. // Журн. физ. химии, 2003, т. 77, № 7, с. 1307-1309.

35. James P. J., Antognozzi M., Tamayo J., McMaster T. J., Newton J. M., Miles M. J. // Langmuir, 2001, vol. 17 , p. $349-360$. 


\title{
AFM-ANALYSIS OF THE SURFACE OF THE PROFILED SULFOCATION-EXCHANGE MEMBRANE AFTER ITS CONTACT WITH PHENYLALANINE
}

\author{
(C) 2018 E. A. Goleva, V. I. Vasil'eva, E. O. Abramova \\ Voronezh State University, 1 Universitetskaya pl., 394018 Voronezh, Russia \\ e-mail:vorobjeva_ea@mail.ru \\ Received 01.08.2018
}

\begin{abstract}
The AFM analysis of surface roughness of ion-exchange membranes is of great practical importance, since surface properties affect operational, physico-chemical, transport and equilibrium characteristics. The purpose of this work is to find out the influence of alkylaromatic amino acid phenylalanine on the surface properties (microrelief and roughness) of the heterogeneous profiled sulfocation-exchange membrane MK-40.

Heterogeneous sulfocation-exchange membrane MK-40pr with geometrically inhomogeneous (profiled) surface was employed as an object of investigations. Investigations of the surface micro-relief of the membrane were performed by atomic force microscopy (AFM) with the use of scanning probe microscope produced by NT-MDT Corporation (model Solver P47 Pro) (Russia, Zelenograd) performed in semi-contact mode applied to the air-dry samples.

The geometrical inhomogeneity of the surface of the profiled sulfocathion-exchange membrane MK$40_{\mathrm{pr}}$ after chemical conditioning and its contact with aqueous solutions of phenylalanine concentration $0.15 \mathrm{~mol} / \mathrm{L}$ for 80 hours was studied by atomic-force microscopy. For membranes after contact with phenylalanine, an increase in the homogenous of the surface is found in comparison with the conditioned membrane sample. This is due to a decrease in the number and size of macropores and large defects on the surface of the membrane due to the sorption of the amino acid.

The analysis of the microprofile surfaces of the membrane MK- $40_{\mathrm{pr}}$ confirms the fact of a decrease in the roughness of its surface in the amino acid form due to the decrease in the water content of the membrane. Absorption of the amino acid promotes the hydrophobization of the membrane surface due to the intensive structure formation in the ion-exchanger - polymer carrier system. Evidence of the hydrophobization of the surface and the decrease in the water content of the membrane in the form of an amino acid is information obtained in the phase contrast regime. Upon transition to the amino acid form, the value of the phase shift of the probe oscillations and the number of light regions characterizing the hydrophobicity of the membrane surface sharply increase.

The effect of phenylalanine on the properties of the surface is in the decrease of all the amplitude roughness parameters of the surface of the conditioned membrane MK- $40_{\mathrm{pr}}$. Image of the surface for the conditioned sample of sulfocation-exchange membrane MK-40pr appears as a developed chaotic structure with micrometer-scaled roughness: arithmetical mean roughness $R_{\mathrm{a}}$ fits with $186.4 \mathrm{~nm}$ at $R_{\mathrm{z}}=953.1 \mathrm{~nm}$. Surface of the MK- $40_{\mathrm{pr}}$ membrane after its contact with phenylalanine has a more smoothed relief: surface roughness $R_{\mathrm{z}}$ fitted with $745.0 \mathrm{~nm}$, while ariythmetical mean scale of roughness $R_{\mathrm{a}}-172.8 \mathrm{~nm}$.

The correlation of the histograms the heights density distributions on the surface revealed that the narrower distribution of heights is typical for the conditioned membrane sample. As for the conditioned sample of MK-40pr membrane the maximum density corresponds to the mean value of the surface roughness equal to $1 \mu \mathrm{m}$, while for the sample of membrane after its contact with phenylalanine histogram is characterized by a spread maximum and a decrease of the mean roughness value up to $0.6-0.8 \mu \mathrm{m}$, as well.
\end{abstract}

Keywords: profiled sulfocation-exchange membrane, atomic force microscopy, phenylalanine.

DOI: DOI: https://doi.org/10.17308/kcmf.2018.20/578 


\section{ACKNOWLEDGMENTS}

This work was financially supported by RFBR grant (project No 18-08-01260).

AFM images of the membrane surface were obtained on the equipment of the Collective Use Center of Voronezh State University. URL: http://ckp.vsu.ru.

\section{REFERENCES}

1. Berezina N. P., Kononenko N.A. Structural Organization of Ion-Exchange Membranes. Krasnodar, Kuban. State University Publ., 1996, 49 p. (in Russ.)

2. Pevnickaya M. V., Varencov V. K., Urusov K. H. Izv. SO AN SSSR. Ser.Him. Nauk, 1969, iss. 6, no. 4, pp. 18-24. (in Russ.)

3. Varencov V. K., Pevnickaya M. V. Izv. SO AN SSSR. Ser. Him. Nauk, 1973, iss. 2, no. 4, pp. 3-8. (in Russ.)

4. Pismenskaya N. D., Nikonenko V. V., Belova E. I., Lopatkova G. Yu., Sistat Ph., Pourcelly G., Larshe K. Rus. J. Electrochem., 2007, vol. 43, no. 3, pp. 325-345. DOI: 10.1134/S102319350703010X

5. Goleva E. A., Vasil'eva V. I. Proceedings of Voronezh State University. Series: Chemistry. Biology. Pharmacy, 2012, no. 1, pp. 33-38. Available at: http://www. vestnik.vsu.ru/pdf/chembio/2012/01/2012-01-06.pdf (in Russ.)

6. Sazanova T. S., Vorotyntsev I. V., Kulikov B. V., Davletbaeva I. M., Zaripov I. I. Membrany i membrannye tekhnologii [Petroleum Chemistry], 2016, vol. 6, no. 2, pp. 307-327. DOI: 10.1134/S2218117216020115 (in Russ.)

7. Tamime R., Wyart Y., Siozade L., Baudin I., Deumie C., Glucina K., Moulin P. Membranes, 2011, vol. 1, pp. 9197. DOI:10.3390/membranes 1020091

8. Volfkovich Yu. M., Filippov A. N., Bagotsky V. S. Structural Properties of Porous Materials and Powders Used in Different Fields of Science and Technology. London, Springer-Verlag, 2014, p. 300.

9. Vasil'eva V. I., Goleva E. A. J. Surf. Investigation. X-ray, Synchrotron and Neutron Techniques, 2013, vol. 7, no. 3, pp. 542-546. DOI: 10.1134/S1027451013030373

10. Vasil'eva V. I., Kranins N. A., Malykhin M. D., Akberova E. M., Zhiltsova A. V. J. Surf. Investigation. X-ray, Synchrotron and Neutron Techniques, 2013, vol. 7, no. 1, pp. 144-153. DOI: 10.1134/S1027451013010321

11. Yatsev A. M., Akberova E. M., Goleva E. A., Vasil'eva V. I., Malykhin M. D. Sorption and Chromatographic Processes, 2017, vol. 17, no. 2, pp. 313-322. Available at: http://www.sorpchrom.vsu.ru/articles/20170219.pdf (in Russ.)

12. Pismenskaya N. D. Diss. doct. chem. nauk. Krasnodar, 2004, 405 p. (in Russ.)

13. Lopatkova G. Yu. Diss. cand. chem. nauk. Krasnodar, 2006, 180 p. (in Russ.)

14. Zajchenko N. A., Vasil'eva V. I., Grigorchuk O. V., Grechkina M. V., Bogatikov E. V. Proceedings of Voronezh State University. Series: Chemistry. Biology. Pharmacy,
2009, no. 1, pp. 7-16. Available at: http://www.vestnik.vsu. ru/pdf/chembio/2009/01/2009-01-01.pdf (in Russ.)

15. Vasil'eva V. I., Pismenskaya N. D., Akberova E. M., Nebavskaya K. A. Rus. J. Phys. Chem. A., 2014, vol. 88, no. 8, pp. 1293-1299. DOI: 10.1134/S0036024414080317

16. Vasil'eva V. I., Bityuckaya L. A., Zajchenko N. A., Grechkina M. V., Botova T. S., Agapov B. L. Sorption and Chromatographic Processes, 2008, vol. 8, no. 2, pp. 260 271. Available at: http://www.sorpchrom.vsu.ru/articles/20080210.pdf (in Russ.)

17. Krisilova E. V., Eliseeva T. V., Oros G. Yu. Prot. Met. Phys. Chem. Surf., 2011, vol. 47, no. 1, pp. 39-42. DOI: $10.1134 / \mathrm{S} 2070205111010072$

18. Suwal S., Roblet C., Amiot J., Bazinet L. Sep. Purif. Technol., 2015, vol. 147. pp. 227-236. DOI: 10.1016/ j.seppur.2015.04.014

19. Kharina A. Yu. Diss. cand. chem. nauk. Voronezh, 2017, 162 p. (in Russ.)

20. Zabolotskii V. I., Loza S. A., Sharafan M. V. Patent RF, no. 2284851, 2006. (in Russ.)

21. Zabolotskii V. I., Loza S. A., Sharafan M. V. Rus. J. Electrochem., 2005, vol. 41, no. 10. pp. 1053-1060. DOI: 10.1007/s11175-005-0180-2

22. Berezina N. P., Kononenko N. A., Dvorkina G. A., Shel'shedov N. V. Physical-Chemical Properties of IonExchange Materials. Krasnodar, Kuban. Gos. Univ. Publ., 1999, 82 p. (in Russ.)

23. Rykov S. A. Scanning Probe Microscopy of Semiconductor Materials and Nanostructures. Saint-Petersburg, Nauka Publ., 2001, 53 p. (in Russ.)

24. Khulbe K. C., Feng C. Y., Matsuura T. Synthetic Polymeric Membranes. Characterization by Atomic Force Microscopy. Berlin Heidelberg, Springer_Verlag, 2008, $197 \mathrm{p}$.

25. Scanning Probe Microscopy of Biopolymers / Ed. I. V. Yaminsky. Moscow, Nauchnyj Mir Publ., 1997, 88 p. (in Russ.)

26. Surface Roughness. Parameters and Characteristics. GOST 2789-73. Enter. 1973-04-23. Moscow, Izd-vo standartov Publ., 1973, 6 p. (in Russ.)

27. Krisilova E. V., Eliseeva T. V., Selemenev V. F. Rus. J. Phys. Chem. A., 2009, vol. 83, no. 11, pp. 1954-1956. DOI: $10.1134 / \mathrm{S} 0036024409110235$

28. Krisilova E. V., Eliseeva T. V., Selemenev V. F. Sorption and Chromatographic Processes, 2009, vol. 9, no. 5, pp. 671-676. Available at: http://www.sorpchrom.vsu. ru/articles/20090511.pdf (in Russ.)

29. Kotova D. L., Selemenev V. F. Thermal Analysis of Ion-Exchange Materials. Moscow, Nauka Publ., 2002, 156 p. (in Russ.)

30. Goleva E. A., Vasil'eva V. I., Selemenev V.F., Kuznetsov V. A., Ostankova I. V. Sorption and Chromatographic Processes, 2016, vol. 16, no. 5, pp. 640-652. Available at: http://www.sorpchrom.vsu.ru/articles/20160509.pdf (in Russ.) 
31. Laskorin B. N., Semenova E. I., Smirnova N. M. Synthesis and Properties of Ion-Exchange Materials. Moscow, Nauka Publ., 1968, 10 p.

32. Trunaeva E. S., Khokhlova O. N., Khokhlov V. Yu. J. Struc. Chem., 2015, vol. 56, no. 6, pp. 1058-1062. DOI: 10.1134/S0022476615060050

33. Vasil'eva V. I., Goleva E. A., Selemenev V. F. Rus. J. Phys. Chem. A., 2016, vol. 90, no. 10, pp. 2035-2043. DOI: $10.1134 / \mathrm{S} 0036024416100277$
34. Kotova D. L., Krysanova T. A., Rozhnova O. I. Russ J. Phys. Chem., 2003, vol. 77, no. 7, pp. 1175-1177. Available at: https://elibrary.ru/item.asp?id=13425703

35. James P. J., Antognozzi M., Tamayo J., McMaster T. J., Newton J. M., Miles M. J. / Langmuir, 2001, vol. 17, pp. 349-360. DOI: 10.1021/la000332h Available at: https:// www.physics.uoguelph.ca/psi/papers/AFM/James Lang01. pdf
Голева Елена Алексеевна - к. х. н., ведущий инженер кафедры аналитической химии химического факультета, Воронежский государственный университет; e-mail: vorobjeva_ea@mail.ru

Васильева Вера Ивановна - д. х. н., профессор кафедры аналитической химии, Воронежский государственный университет; e-mail: viv155@mail.ru

Абрамова Екатерина Олеговна - студентка кафедры аналитической химии химического факультета, Воронежский государственный университет
Elena A. Goleva - Cand. Sci. (Chem.), Leading Engineer of the Analytical Chemistry Department, Voronezh State University; e-mail: vorobjeva_ea@ mail.ru

Vera I. Vasil'eva - Dr. Sci. (Chem.), Professor of the Analytical Chemistry Department, Voronezh State University; e-mail: viv155@mail.ru

Ekaterina O. Abramova - the student of the Analytical Chemistry Department, Voronezh State University 